\title{
The Effect of Maize Grain Size on the Physicochemical Properties of Isolated Starch, Crude Maize Flour and Nixtamalized Maize Flours
}

\author{
Lineth J. Vega-Rojas' ${ }^{1}$, Margarita Contreras-Padilla ${ }^{2,3}$, Natalia Rincon-Londoño ${ }^{4}$, \\ Alicia del Real López ${ }^{3}$, Rosa M. Lima-Garcia ${ }^{3}$, Natalia Palacios-Rojas 5 , \\ Mario E. Rodriguez-Garcia ${ }^{3,6^{*}}$ \\ ${ }^{1}$ Maestría en Ciencias Químico-Biológicas, Facultad de Química, Universidad Autónoma de Querétaro, \\ Querétaro, México \\ ${ }^{2}$ División de Investigación y Posgrado, Facultad de Ingeniería, Universidad Autónoma de Querétaro, Cerro de \\ las Campanas s/n, Las Campanas Santiago de Querétaro, Querétaro, México \\ ${ }^{3}$ Departamento de Nanotecnología, Centro de Física Aplica y Tecnología Avanzada, Universidad Nacional \\ Autónoma de México, Campus Juriquilla, Querétaro, México \\ ${ }^{4}$ Posgrado en Ciencia e Ingeniería de Materiales, Centro de Física Aplica y Tecnología Avanzada, Universidad \\ Nacional Autónoma de México, Campus Juriquilla, Querétaro, México \\ ${ }^{5}$ International Maize and Wheat Improvement Center (CIMMYT), Km 45 Carretera México-Veracruz, Texcoco, \\ México \\ ${ }^{6}$ Licenciatura en Ingeniería Física, Facultad de Ingeniería, Universidad Autónoma de Querétaro, Querétaro, \\ México \\ Email: *marioga@fata.unam.mx
}

Received 10 December 2015; accepted 26 February 2016; published 29 February 2016

Copyright (C) 2016 by authors and Scientific Research Publishing Inc.

This work is licensed under the Creative Commons Attribution International License (CC BY).

http://creativecommons.org/licenses/by/4.0/

c) (i) Open Access

\begin{abstract}
Usually, the maize cob is formed by grains of medium size. However, the extremes have larger or smaller size grains. The objective of this study was to investigate the influence of grain size from the same hybrid on the physicochemical properties of isolated starch, crude maize flours and nixtamalized maize flours. Two hybrids, one from CIMMyT-Mexico called IMIC-254 and one commercial sample from Monsanto (Puma) were studied. The isolated starch granules from small, medium, and large grains exhibit the same size and distribution. The grain size has influence in the determination of cooking and steeping times; small grains reach these parameters faster than medium and large ones. The hardness of the grain size for both hybrids does not showed statistic-
\end{abstract}

${ }^{*}$ Corresponding author.

How to cite this paper: Vega-Rojas, L.J., et al. (2016) The Effect of Maize Grain Size on the Physicochemical Properties of Isolated Starch, Crude Maize Flour and Nixtamalized Maize Flour. Agricultural Sciences, 7, 114-125.

http://dx.doi.org/10.4236/as.2016.72011 
al differences between them. The starch from small, medium and large grains is mainly composed of amylopectin; this result is confirmed by $\mathrm{X}$-ray diffraction and Megazine analysis. The apparent viscosity of the isolated starches of small grains showed statistically significant higher peak values. According to these results, it is possible to use small, medium, and large grains to obtain products with the same physicochemical properties, by adjusting the cooking and steeping times and $\mathrm{Ca}^{2+}$ content.

\section{Keywords}

Maize Grain Size, Nixtamalization, Starch, Rheological Properties

\section{Introduction}

Due to grain size, processing of maize for nixtamalized products must be adjusted to ensure the best yielding and quality of the final products. Maize grain size is influenced by several factors including agronomical and environmental conditions, genetic background, among others. These factors could affect the physicochemical composition of the maize grains and, therefore, affect their functionality [1]-[3]. On the other hand, it is well known that there are different grain sizes within each maize cob.

In Mexico, there is a high dependence on maize. Approximately $75 \%$ of its consumption is in the form of tortillas, snacks, tamales, among others. The tortilla production is obtained by a process named nixtamalization that involves a thermo-alkaline treatment, where maize grains are cooked and steeped in an oversaturated calcium hydroxide solution [4]. During the alkaline process (cooking and steeping), there is a calcium concentration gradient through the pericarp, germ, and endosperm structures of the maize grain [5]. This process promotes physicochemical changes in the pericarp, germ, and endosperm, and gives, as a result, changes in the final products such as nixtamalized instant corn flours [6] and traditional products. Usually, the nixtamalization process is carried out with uniform grains.

In the case of traditional and industrial nixtamalization process, the influence of the grain size on parameters such as cooking time, moisture, viscosity, and calcium content has not been studied. It is believed that the starch obtained from large grains can be better or has differences in the amylose and amylopectin content. During the storage process, there exists a step in which small and large grains are separated to obtain a uniform size that guaranty the uniformity during the process.

The pasting properties of maize starch are influenced by intrinsic parameters such as the botanical source, the content of amylose, amylopectin, fat, protein; the starch granule size and shape, the original order of the amylose and amylopectin inside of the starch granule; and by extrinsic parameters such as extraction method, drying process, and storage. To determine, the functionality of the grains with different sizes is critical to study their physicochemical properties.

The objective of this study was to investigate the influence of the maize grain size on the physicochemical properties of isolated starch, crude maize flours, and nixtamalized flours using two different hybrids, one from CIMMyT-Mexico and one commercial Puma from Monsanto. The chemical proximate analysis was used to determine the protein, fiber, and fat content. Amylose and total starch were determined using Megazyme kit. Atomic absorption spectroscopy was carried out to determine calcium content in nixtamalized samples obtained from small, medium, and large maize grains. Scanning electron microscopy was used to observe the starch morphology; X-ray diffraction analysis was carried out to identify crystalline structures such as amylose and amylopectin in isolated starch. Differential scanning calorimetric was used to study the gelatinization of starch; apparent viscosity was conducted to analyze the pasting properties of isolated, crude maize flour, and nixtamalized maize flours.

\section{Materials and Methods}

Corn grains of two white hybrids were used for this study. One of the hybrids (IMIC-254) was grown in Tlaltizapan, Morelos $\left(18^{\circ} 41^{\prime} \mathrm{N}, 99^{\circ} 07^{\prime} \mathrm{W}\right.$; 945 meters above the sea level; average annual temperature $23.5^{\circ} \mathrm{C}$; average annual precipitation $840 \mathrm{~mm}$, during winter cycle of 2014. The plot size was $5 \mathrm{~m} \times 1$ row and plant densities 
were approximately 66,670 plants $\cdot \mathrm{ha}^{-1} 0.75 \mathrm{~m}$ between rows and $0.20 \mathrm{~m}$ between plants within a row); and the other one was Puma hybrid from Monsanto harvest in Sonora in 2014. Both grains were grown under controlled irrigation conditions, after harvesting and drying, shelled maize grains were separated according to their weight in three different grain sizes: small, medium, and large ones (see Table 1).

\subsection{Crude Maize Flour Preparation}

Whole grains (50 gr of each of the grain size groups) for IMIC-254 and Puma, were ground using a coffee miller (Krups, USA) and the flours were passed through a US 60 sieve.

\subsection{Isolation of Maize Starches}

The small, medium, and large maize grains of IMIC-254 and Puma hybrids were soaked for $12 \mathrm{~h}$ in distilled water at $4^{\circ} \mathrm{C}$. Then the germ and pericarp of these samples (100 g) were manually removed. The bare endosperm was blended at high speed for 2 minutes using a stainless steel blender (Osterizer). The slurry was washed through a $60(0.417 \mathrm{~mm})$ and $100(0.147 \mathrm{~mm})$ US sieves. The filtered product was centrifuged at $25,000 \times \mathrm{g}$ for 20 minutes; the resulting supernatant was decanted. The isolated starch granules were washed three times with distilled water and then dried in a vacuum oven using $1.33 \mathrm{~Pa}$ and $40^{\circ} \mathrm{C}$, the dehydration process was carried out for $8 \mathrm{~h}$. Finally, the dried starch was ground, passed through US100 sieve, and packed until use.

\subsection{Chemical Proximate Analysis}

The crude protein of small, medium, and large maize grains from IMIC-254 and Puma hybrids, as well as the protein of the isolated starches of small, medium, and large maize grains $(\mathrm{N} \times 6.25)$ was measured by the micro-Kjeldahl [7], Moisture [8], total ether extract [9], and ashes [10], crude fiber [8]. All the measurements were done in triplicates.

\subsection{Particle Size of Isolated Maize Starch}

The particle size of isolated starches from small, medium, and large maize grains for IMIC-254 and Puma hybrids was determined using Mastersizer MS2000 of Malvern Company (United Kingdom). The test was carried out using dry dispersion module in a vacuum (Scirocco), with 2 bars of pressure and feed rate $50 \%$. 6 g of maize starch was used of each size. The reported value corresponds to the average of three measurements.

\subsection{Amylose and Starch Determination}

The starch and amylose content was determined using the commercial kit from Megazyme, assays K-TSTA and K-AMYL respectively, (Ireland International, Ltd., Bray, Ireland) according to the manufacturer procedure [11] [12].

\subsection{Physical Properties of the Maize Grains}

The weight of the small, medium, and large grains was determined using an Ohaus Voyager weight scale (0.0001 g)

Table 1. Physical and chemical characterization of small, medium, and large maize grains.

\begin{tabular}{|c|c|c|c|c|c|c|c|c|c|}
\hline Grains & Large (mm) & $\begin{array}{c}\text { Thickness } \\
\text { (mm) }\end{array}$ & $\begin{array}{l}\text { Width } \\
\text { (mm) }\end{array}$ & Weight (g) & $\begin{array}{c}\text { Protein } \\
(\%)\end{array}$ & Fat (\%) & Ash (\%) & $\begin{array}{c}\text { Hectolitre } \\
\text { weight } \\
\text { (Kg/L) }\end{array}$ & $\begin{array}{c}\text { Crude } \\
\text { fiber } \\
(\%)\end{array}$ \\
\hline Small-IMIC & $9.72 \pm 0.86^{\mathrm{c}}$ & $7.96 \pm 0.78^{\mathrm{b}}$ & $2.56 \pm 0.63^{\mathrm{b}}$ & $0.258 \pm 0.052^{c}$ & $8.99 \pm 0.13^{b}$ & $2.96 \pm 0.14^{\mathrm{c}}$ & $1.28 \pm 0.07^{\mathrm{b}}$ & $0.781 \pm 0.119^{a}$ & $1.8 \pm 0.1^{\mathrm{b}}$ \\
\hline Medium-IMIC & $10.96 \pm 0.64^{b}$ & $8.81 \pm 0.45^{\mathrm{a}}$ & $3.02 \pm .47^{\mathrm{a}}$ & $0.343 \pm 0.022^{\mathrm{b}}$ & $8.91 \pm 0.11^{\mathrm{c}}$ & $3.93 \pm 0.09^{\mathrm{a}}$ & $1.35 \pm 0.05^{\mathrm{a}}$ & $0.754 \pm 0.121^{\mathrm{b}}$ & $1.8 \pm 0.2^{\mathrm{a}}$ \\
\hline Large-IMIC & $11.21 \pm 0.55^{\mathrm{a}}$ & $8.82 \pm 0.45^{\mathrm{a}}$ & $3.16 \pm 0.45^{\mathrm{a}}$ & $0.402 \pm 0.023^{\mathrm{a}}$ & $9.41 \pm 0.11^{\mathrm{a}}$ & $3.89 \pm 0.12^{b}$ & $1.33 \pm 0.02^{\mathrm{a}}$ & $0.681 \pm 0.105^{c}$ & $1.9 \pm 0.1^{\mathrm{a}}$ \\
\hline Small-Puma & $8.75 \pm 0.08^{c}$ & $6.25 \pm 0.07^{c}$ & $2.18 \pm 0.49^{c}$ & $0.296 \pm 0.047^{c}$ & $8.85 \pm 0.17^{b}$ & $3.24 \pm 0.11^{\mathrm{b}}$ & $1.28 \pm 0.07^{\mathrm{b}}$ & $0.757 \pm 0.109^{a}$ & $2.4 \pm 0.2^{c}$ \\
\hline Medium-Puma & $9.98 \pm 0.07^{\mathrm{b}}$ & $7.08 \pm 0.06^{\mathrm{b}}$ & $3.33 \pm 0.04^{\mathrm{a}}$ & $0.342 \pm 0.035^{\mathrm{b}}$ & $8.63 \pm 0.12^{c}$ & $3.41 \pm 0.14^{\mathrm{c}}$ & $1.35 \pm 0.05^{\mathrm{a}}$ & $0.732 \pm 0.111^{\mathrm{b}}$ & $2.7 \pm 0.2^{b}$ \\
\hline Large-Puma & $11.41 \pm 0.09^{\mathrm{a}}$ & $7.96 \pm 0.05^{\mathrm{a}}$ & $2.66 \pm 0.45^{\mathrm{b}}$ & $0.420 \pm 0.048^{\mathrm{a}}$ & $9.81 \pm 0.21^{\mathrm{a}}$ & $3.58 \pm 0.10^{\mathrm{a}}$ & $1.34 \pm 0.02^{\mathrm{a}}$ & $0.714 \pm 0.115^{c}$ & $2.7 \pm 0.2^{\mathrm{a}}$ \\
\hline
\end{tabular}


and reported as the average value of 500 grains. Thickness, width, and length of the maize grains were determined using a homemade imaging analysis system that determines the parameters mentioned above for 5 grains at the same time. The reported values correspond to the average of 500 grains.

\subsection{Mechanical Properties}

The breaking force of small, medium, and large maize grains samples for IMIC-254 and Puma hybrids was carried out using a Zwick Roell, model Z005. The penetration test was performed using the side that shows the germen in front of the penetrator. A $200 \mathrm{~N}$ load cell was used, and $2 \mathrm{~mm} / \mathrm{min}$ speed. 50 maize grains were used per sample.

\subsection{X-Ray Diffraction Characterization of Starch}

The X-ray diffraction patterns of amylose (Sigma-Aldrich A-7043, 70\% purity, USA), amylopectin (Sigma-Aldrich 101220, 75\% purity, USA), as well as the isolated starch from small, medium, and large maize grains for IMIC-254 and Puma, were studied. The samples were ground to a fine powder and passed through a 147- $\mu \mathrm{m}$ screen. The powder samples were then densely packed into an aluminum frame. The X-ray diffraction patterns of the samples were recorded on a diffractometer (Rigaku, miniflex) operating at $35 \mathrm{kV}$ and $15 \mathrm{~mA}$, with a $\mathrm{Cu}$ $\mathrm{K} \alpha$ radiation wavelength of $\lambda=1.5406 \mathrm{~nm}$, and from $5^{\circ}$ to $70^{\circ}$ on a $2 \theta$ scale with a step size of $0.02^{\circ}$. The measurements were performed at room temperature.

\subsection{Nixtamalization Process}

The small, medium, and large maize grains of IMIC-254 and Puma hybrids were nixtamalized separately following the process described by Gutierrez et al., 2007. In brief: to have a complete control of the nixtamalization process during the cooking and steeping steps and, more importantly, to have a reproducibility of the samples, a nixtamalization computer controlled process (NCCP) was used. In the initial cooking step of the nixtamalization process, each sample was prepared by cooking $0.5 \mathrm{~kg}$ grains in a solution of $1 \mathrm{~L}$ of distilled water and $0.5 \mathrm{~g}$ of calcium hydroxide (1\%, w/w) (reagent powder, Fermont, Monterrey, NL, México). The maize grains were added to the container and heated until $92^{\circ} \mathrm{C}$. When the sample reaches $36 \%$ moisture content, the system was turn off (end of the cooking time), and the temperature gradually decreased. The temperature changes were monitored until the sample reached the chosen steeping time to begin the washing process. The steeping time for each sample was $7 \mathrm{hr}$.

The cooking liquor (nejayote) was drained off and the nixtamal samples were washed twice with water (distilled water was used to avoid Ca interference) using 2:1 (v/w) ratio water-sample by stirring the grains in the wash water for $1 \mathrm{~min}$. Then the samples were milled and dried at $40^{\circ} \mathrm{C}$ for $12 \mathrm{~h}$.

\subsection{Moisture Content during Nixtamalization}

The moisture content of the small, medium, and large maize grains of IMIC-254 and Puma was monitored during the cooking and steeping steps using an infrared heating thermo-balance (Sartorius Moisture AnalyzerMA35). For moisture content determination during the cooking and steeping the maize grains were ground into flour, using an electric coffee bean grinder. Small amounts of maize $(5 \mathrm{~g})$ were extracted from the cooking container, then allowed to cool, and the outside excess water was removed from the grains with paper towels. Aluminum dishes were used for moisture determination. Data was reported in percentage of dry basis. The samples were analyzed in triplicate.

\subsection{Scanning Electron Microscopy}

The morphology of the starches of IMIC-254 and Puma hybrids for small, medium, and large maize grains were performed with a high vacuum scanning electron microscope (JEOL, JSM-6060LV) with a resolution of 5nm in $\mathrm{HV}$ mode. Before the analysis, the samples were fixed on the specimen holder with carbon tape and mounted on a bronze specimen holder. The analyses conditions used $20 \mathrm{kV}$ electron acceleration voltage and $12-20 \mathrm{~Pa}$ of pressure in the specimen chamber obtaining the images with the secondary electron signal. 


\subsection{Calcium Content}

The calcium content in nixtamalized samplesIMIC-254 and PUMA obtained from larger, medium, and small maize grains, as well as the endogenous calcium in the maize kernel was determined by the dry ashing method [8] and the methodology reported by Gutierrez et al. [4] and Valderrama-Bravo et al. [13]. The residual calcium content was measured with a double-beam atomic absorption spectrometer (Analyst 300 Perkin Elmer) equipped with a deuterium lamp, background corrector and a hollow cathode lamp. A calcium standard (1000 ppm) was used to elaborate a calibration curve with a certified reference (High purity standards, USA, corn meal-solid Allen Bros. Milling Co.). The average from three measurements for each sample was reported.

\subsection{Apparent Viscosity}

In order to determine the apparent viscosities of the isolated starch, crude maize flours, and nixtamalized-water suspensions from small, medium, and large maize samples of IMIC-254 and Puma hybrids, pasting profiles were obtained. Crude maize flours and nixtamalized samples were obtained from the sample retained in the US mesh 60; while isolated starches were passed through the US mesh 100. The pasting profiles were determined using a Rheometer MCR-102 (Anton Paar, Germany), 3 g of starch and 18 mL of water (85.3\% moisture) sample was tested using the following thermal profile: the temperature of the system was $50^{\circ} \mathrm{C}$, and it remained constant for $1 \mathrm{~min}$. Then the sample was heated for $5.3 \mathrm{~min}$ from $50^{\circ} \mathrm{C}$ to $90^{\circ} \mathrm{C}$ and then held at a constant temperature of $90^{\circ} \mathrm{C}$ for $5.3 \mathrm{~min}$. The sample was cooled down to $50^{\circ} \mathrm{C}$ in $5.3 \mathrm{~min}$., and this temperature was kept constant for $2 \mathrm{~min}$. The total time for this test was 23 minutes. Three different measurements were done. The frequency operation was $194 \mathrm{rpm}$.

\subsection{Differential Scanning Calorimetry}

The DSC curves of isolated starches for IMIC-254 and Puma were measured using the Differential Scanning Calorimeter DSC Q100, TA Instrument. Calibrations were performed using pure indium with a heat of fusion of $28.4 \mathrm{~J} / \mathrm{g}$ and a melting temperature of $56.66{ }^{\circ} \mathrm{C}$. Samples of $6.0 \pm 0.1 \mathrm{mg}$ were prepared by adding deionized water to the mafafa starch into the pan until it reached a moisture of $85 \%(\mathrm{w} / \mathrm{w})$. The pans were hermetically sealed and kept at room temperature for $12 \mathrm{hrs}$ and then, the samples were scanned from $30^{\circ} \mathrm{C}$ to $110^{\circ} \mathrm{C}$ at $7.5^{\circ} \mathrm{C} / \mathrm{min}$. An empty aluminum pan was used as a reference. During the scans, the space surrounding the sample chamber was filled with dry nitrogen. For each thermogram, the gelatinization transition parameters were measured using a DSC software (Universal Analysis 2000 TA Instruments). These values were referred as onset (T0), mid-point (Tp), and end (Te) temperatures and enthalpy of gelatinization $(\Delta \mathrm{H})$. Each experiment was conducted in duplicate.

\section{Results and Discussion}

\subsection{Physico-Chemical Characterization of Maize Grains}

The percentage of small, medium, and large maize grains for IMIC-254 was $10.50 \% \pm 2.23 \%, 64.07 \% \pm 1.56 \%$, and $22.33 \% \pm 1.23 \%$, while for Puma was $13.50 \% \pm 1.33 \%, 60.25 \% \pm 1.56 \%$, and $29.03 \% \pm 1.12 \%$ : This result indicates that medium grains mainly from the maize cob of these hybrids. Significant differences were found in length and weight of the 3 groups of maize grains analyzed. Small grains were statistically different in width compared to large ones. No significant differences were observed for kernel thickness.

Chemical proximate analyzes of small, medium, and large maize grains as well as the physical dimensions for both hybrids are shown in Table 1 . Moisture of all grains was in the range of $10 \%-11 \%$. According to these data, IMIC-254 and Puma large maize grains contain more protein, while a lower fat content was found for small grains of both strains. This fact could be due to the germ development. Ash content is lower in small grains for both samples. Ash content was similar in the three groups of analyzed maize grains. In the case of crude fiber, large and medium grains for IMIC-254 and PUMA showed statistical differences about the small ones. A Puma grains showed more fiber content about IMIC-254.

\subsection{Starch and Amylose Characterization}

The protein, fat, ash, and moisture content of isolated starches from small, medium and large maize grains for 
IMIC-254 and PUMA grains, as well as their amylose and starch content for small, medium, and large starches is shown in Table 2. According to this table, and taking into account the values reported in Table 1, the isolation process reduce the protein content and almost eliminate the fat content in both samples, the protein content in isolated starches increases with the grain size. The fat and ash content exhibits statistical differences while the starch content in isolated granules was found to be greater bigger for small starch grains. The amylose content is lower in the case of isolated starch from large maize grains from IMIC-254 and PUMA. It means that both grains are formed mainly by amylopectin.

\subsection{Particle Size Distribution}

Figures 1(a)-(c) shows the particle size distributions (PSD) of isolated starch samples from small, medium, and large maize grains of IMIC-254, its particle size varied from 3.23 to $24.26 \mu \mathrm{m} ; 4.20$ - $23.77 \mu \mathrm{m}$; and 3.40 -
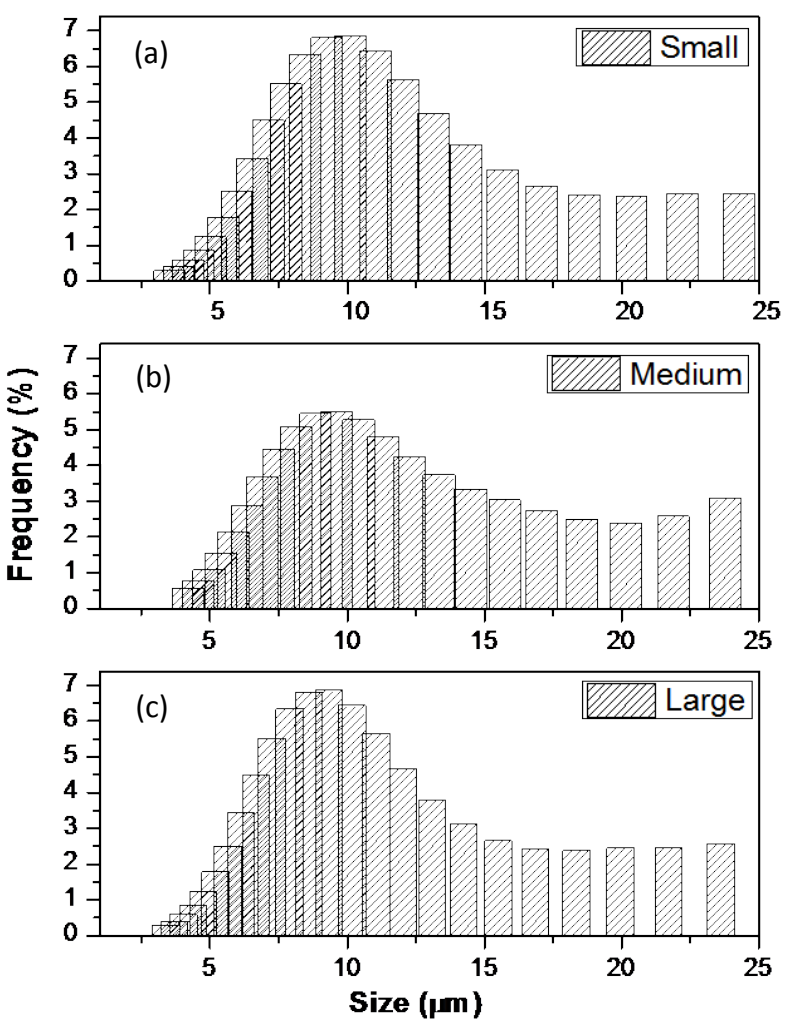

Figure 1. (a)-(c) particle size distributions of isolated starch from small, medium, and large maize grains of IMIC-254.

Table 2. Protein, fat, ash, starch, amylose, and moisture content of isolated starches for IMIC-254 and PUMA hybrids from small, medium and large maize grains.

\begin{tabular}{ccccccc}
\hline Isolated Starch & Protein (\%) & Fat (\%) & Ash (\%) & Starch (\%) & Amylose (\%) & Moisture (\%) \\
\hline Small IMIC-Starch & $6.36 \pm 0.13^{\mathrm{c}}$ & $0.04 \pm 0.01^{\mathrm{a}}$ & $0.46 \pm 0.02^{\mathrm{c}}$ & $83.15 \pm 0.85^{\mathrm{a}}$ & $32.61 \pm 1.02^{\mathrm{a}}$ & $9.49 \pm 0.09^{\mathrm{a}}$ \\
Medium IMIC-Starch & $6.84 \pm 0.11^{\mathrm{b}}$ & $0.09 \pm 0.02^{\mathrm{b}}$ & $0.82 \pm 0.08^{\mathrm{a}}$ & $75.02 \pm 1.02^{\mathrm{b}}$ & $32.31 \pm 1.23^{\mathrm{a}}$ & $9.69 \pm 0.11^{\mathrm{a}}$ \\
Large IMIC-Starch & $7.56 \pm 0.09^{\mathrm{a}}$ & $\mathrm{ND}$ & $0.72 \pm 0.03^{\mathrm{b}}$ & $74.65 \pm 1.08^{\mathrm{b}}$ & $27.95 \pm 1.12^{\mathrm{b}}$ & $9.68 \pm 0.10^{\mathrm{a}}$ \\
Small Puma-Starch & $6.06 \pm 0.23^{\mathrm{c}}$ & $\mathrm{ND}$ & $0.38 \pm 0.01^{\mathrm{c}}$ & $82.15 \pm 0.35^{\mathrm{a}}$ & $32.74 \pm 1.02^{\mathrm{a}}$ & $9.60 \pm 0.10^{\mathrm{a}}$ \\
Medium Puma-Starch & $6.64 \pm 0.24^{\mathrm{b}}$ & $\mathrm{ND}$ & $0.79 \pm 0.03^{\mathrm{a}}$ & $74.92 \pm 1.20^{\mathrm{b}}$ & $32.01 \pm 1.23^{\mathrm{a}}$ & $9.62 \pm 0.10^{\mathrm{a}}$ \\
Large Puma-Starch & $7.86 \pm 0.29^{\mathrm{a}}$ & $\mathrm{ND}$ & $0.69 \pm 0.03^{\mathrm{b}}$ & $74.25 \pm 1.08^{\mathrm{b}}$ & $27.15 \pm 1.06^{\mathrm{b}}$ & $9.58 \pm 0.10^{\mathrm{a}}$ \\
\hline
\end{tabular}


$23.62 \mu \mathrm{m}$, while for Puma it was found to range from 5.26 to $21.64 \mu \mathrm{m} ; 5.78$ - $23.56 \mu \mathrm{m}$; and 4.89 - $24.56 \mu \mathrm{m}$ for small, medium, and large isolated starches, respectively. The distribution was centered on $11 \mu \mathrm{m}$. According to this result, all starch granules from IMIC-254 and Puma grains with different sizes exhibit the same starch distribution. Grain size does not influence the isolated starch distribution in these hybrids.

\subsection{SEM Analysis}

Figures 2(a-c) show the SEM images of isolated starch from small, medium, and large IMIC-254 maize grains and Figures 2(d)-(f) show the isolated starch for small, medium and large Puma grains. Polyhedral, spherical, and non-regular starch granules were found. Some of the spherical starches correspond to starch grains coming from the soft endosperm (Gutierrez et al. 2007). Using image analysis, the starch size for all samples varies between 3.4 to $23.89 \mu \mathrm{m}$. These results are in agreement with the data obtained by using PSD. It is important to recall that there is not a linear correlation between starch size and maize size. The starch particle size is an important parameter because it affects the physicochemical properties of the different product obtained.

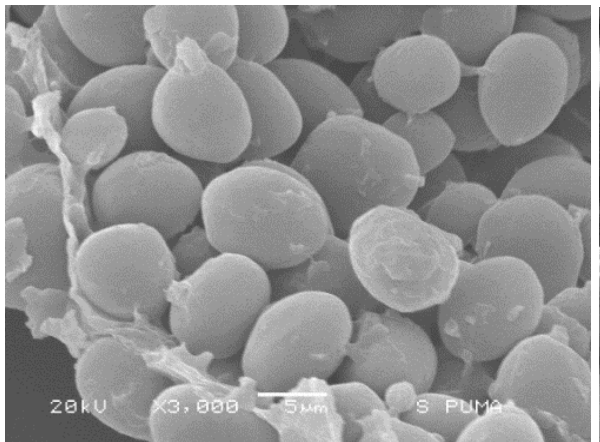

(a)

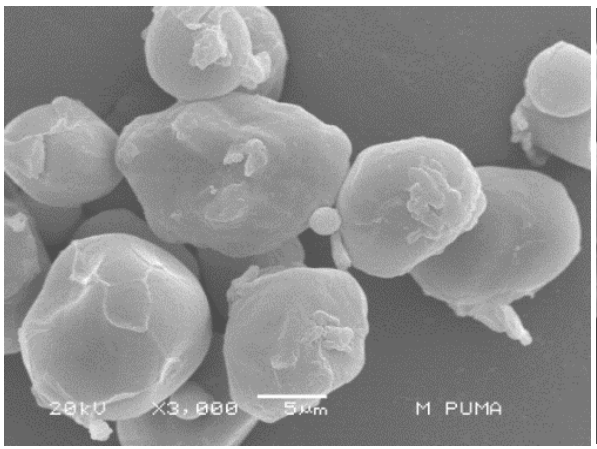

(c)

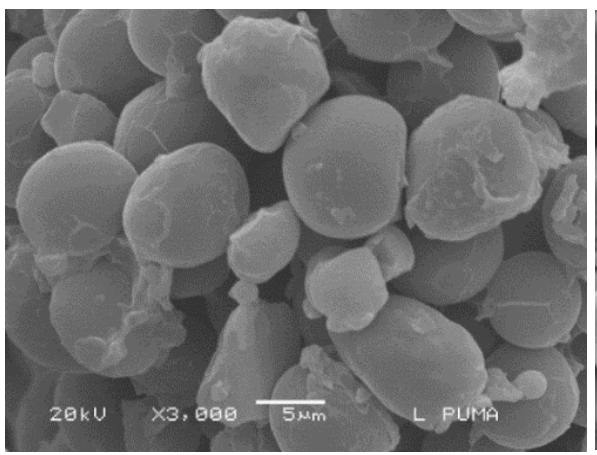

(e)

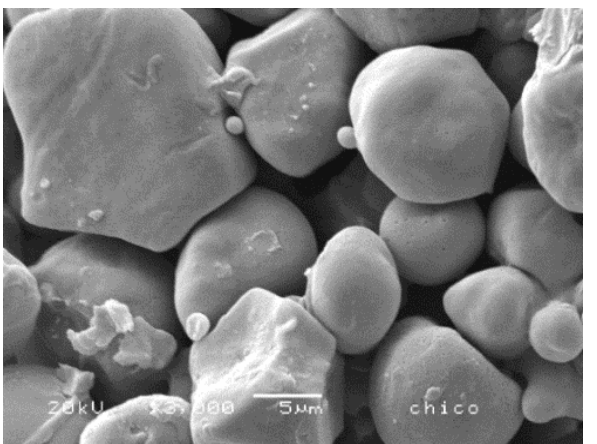

(b)

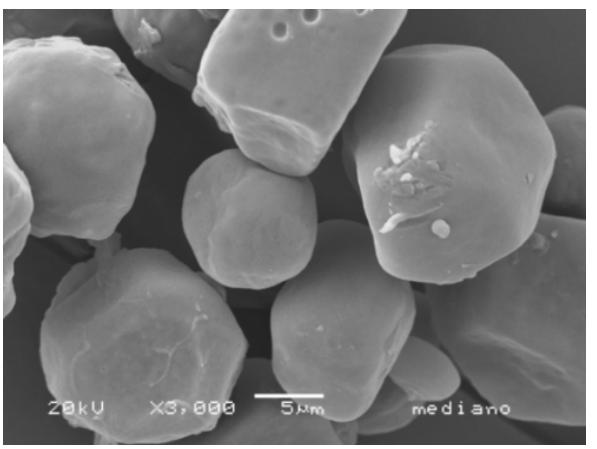

(d)

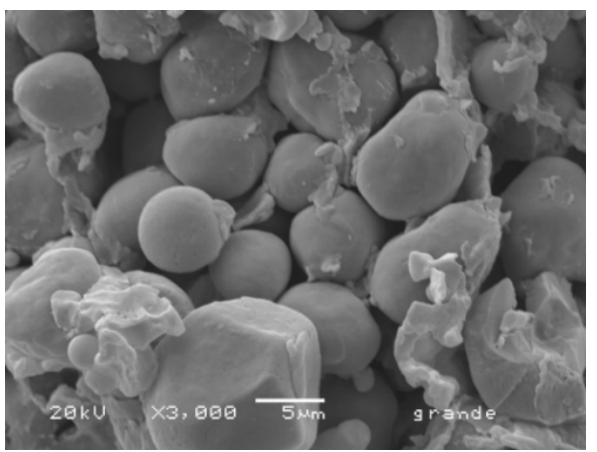

(f)

Figure 2. SEM images of the maize endosperm: (a) floury endosperm; (b) vitreous endosperm; (c) gelatinized floury endosperm; and (d) gelatinized vitreous endosperm for IMIC-254 and Puma maize grains. 


\subsection{Mechanical Properties}

Figure 3 shows the hardness for IMIC-254 and Puma grains. No statistical differences in this parameter for small, medium and large, grains were found. In fact, the penetration test is looking at the hardness of the pericarp. The hardness of the pericarp is influenced by its chemical composition. The moisture content of IMIC-254 and PUMA grains used in this test was around $10 \%$, and this parameter did not affect the hardness of the grain.

\subsection{Cooking Time and Moisture Content}

The cooking time is function of the moisture content and is determined when the sample has $36 \%$ of moisture, and the manual removal of the pericarp is possible. According to this figure, the cooking time for small, medium, and large PUMA maize grains were: 48.7, 49.7, and 51.2 min respectively while for IMIC-254 were 47.8, 54.2, and 54.4. The end of the steeping process corresponds to the moment in which the sample reached $46 \%$ of moisture. The samples reached this point as follows: small, medium and large grains for both maize grains. The moisture content, in this case, can be influenced by the physical state of the grains (presence of fissures, and broken tip cap), the morphology of the maize grains, the thickness of the pericarp, and the amount of protein. Optical inspection of the grains did not show any mechanical damage. As 36\% of moisture is the end of the cooking time, for small grains, the water diffusion is faster, and the cooking time decreases. If the cooking time decreases, the energy consumption decreases too.

\subsection{Calcium Content}

Calcium content in nixtamalized small, medium, and large maize grains for IMIC-254 and PUMA grains is shown in Figure 4: Calcium content in small and medium nixtamalized of IMIC-254 grains is statistically different from the value found in large grains while for PUMA grains no statistical differences were found. It was established that the amount of calcium present in the grain is due to diffusion and percolation of calcium ions into the most internal layers of the endosperm, germ, and pericarp. Additionally, due to the carbonization pro-

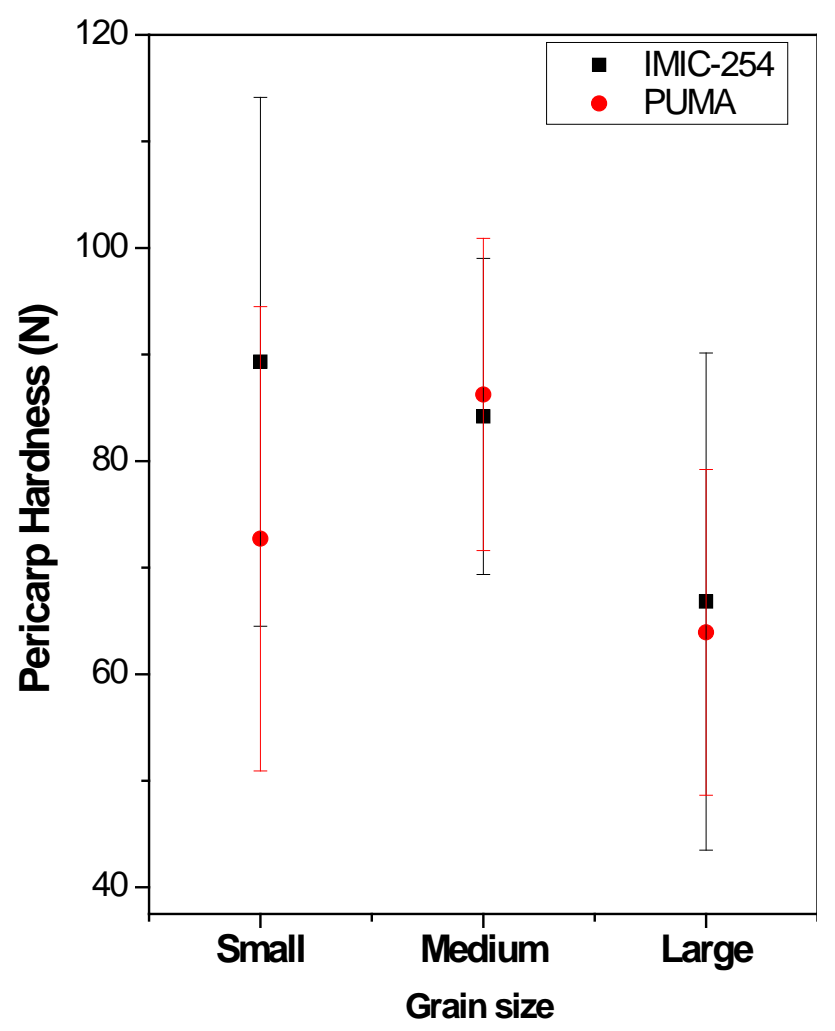

Figure 3. Maize grain hardness from small, medium, and large IMIC-254 and Puma maize grains. 


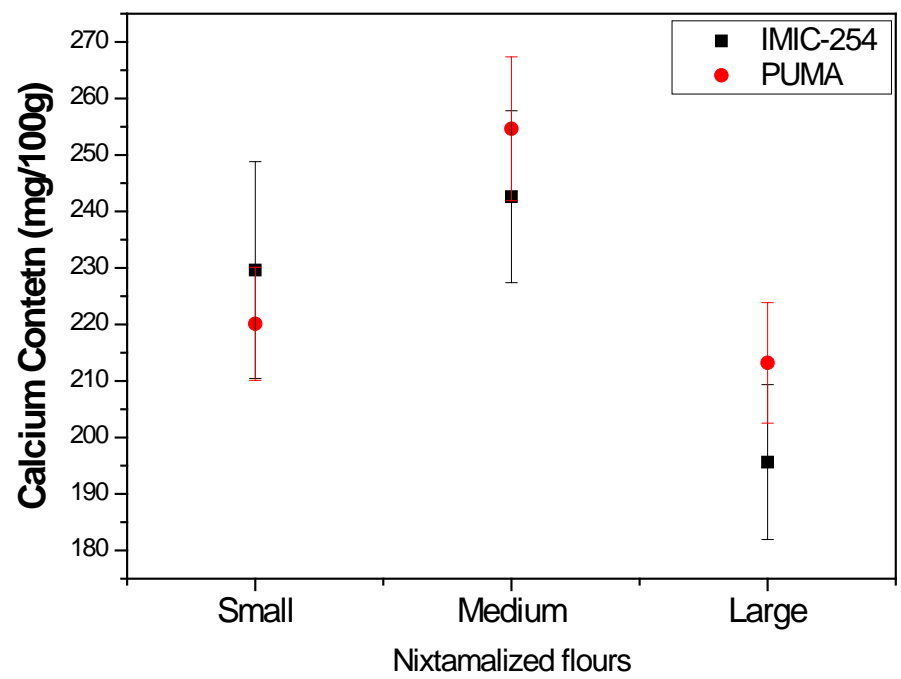

Figure 4. Calcium content in nixtamalized grains: small, medium, and large for IMIC-254 and Puma hybrids.

cess, there exists an accumulation of calcium carbonate on the surface of the pericarp. Taking into account the hardness of the corn grains (Figure 3), there is no correlation between this parameter and calcium content; the end of the cooking time as was mentioned before is characterized by a $46 \%$ of moisture, large maize grains reached this value after medium and small ones. Water and calcium uptake are simultaneous processes, meaning that a positive correlation between these parameters was found (see Figure 5).

\subsection{X-Ray Analysis}

The X-ray diffraction patterns of isolated starches from small, medium, and large IMIC-254 and PUMA maize grains, as well as amylopectin and amylose from Sigma-Aldrich taken as a reference, are shown in Figure 6. The continuous lines in this figure showed the most intense diffraction peaks for amylose, which so far is the only crystalline structure that has been studied and defined ( $\alpha$-amylose 43 - 1858) (JCPDS-International Centre for Diffraction Data 1997) [14]. As can be seen in this figure, starch from small, medium, and large maize grains for IMIC-254 and PUMA does not exhibit the characteristic peaks of amylose located at $19.70^{\circ}(004), 22.25^{\circ}$ (220), and $24.03^{\circ}(130)$. On the other hand, the peak located around $23.106^{\circ}$ is present only in amylopectin standard and in the samples studied; this is an indicative that the starch from these hybrids is formed mainly by amylopectin. This result is in agree to the Megazin test for both maize grains in which it was found that both starches are formed by amylopectin.

\subsection{Apparent Viscosity}

Figure 7 shows the pasting profiles of isolated starch, crude flour, and nixtamalized corn flour obtained from small, medium, and large PUMA maize grains (Figures 7(a)-(c)); and Figures 7(d)-(f) shows the pasting profile for IMIC-254 samples as a function of the time. A pasting profile can be influenced by the particle size, chemical composition of the grain, starch content, amylose and amylopectin ratio. Also, by the physicochemical transformation that take place during the nixtamalization process that gives as a result the increase in the $\mathrm{Ca}^{2+}$ content and gelatinization (pre-gelatinization) for the nixtamalized samples. Isolated starch from puma exhibits a bigger peak viscosity that could be influenced by the amylopectin content (see Table 2). IMIC-254 crude flour does not show an apparent peak viscosity as well as the so call breakdown, and it is directly related to its composition, in the case of nixtamalized flours both samples for small, medium, and large grains showed the same behaviors as a function of the time. According to this figure, the particle size of the starch granule from small, medium, and large grains does not have any influence on the pasting profile (see Figure 2) because no statistical difference between these granules was found. Flours from medium grains in both cases exhibit the biggest peak viscosity. The pasting properties are governed by the thermal changes (gelatinization) produced by the thermo alkaline process and the inclusion of calcium [15]. 


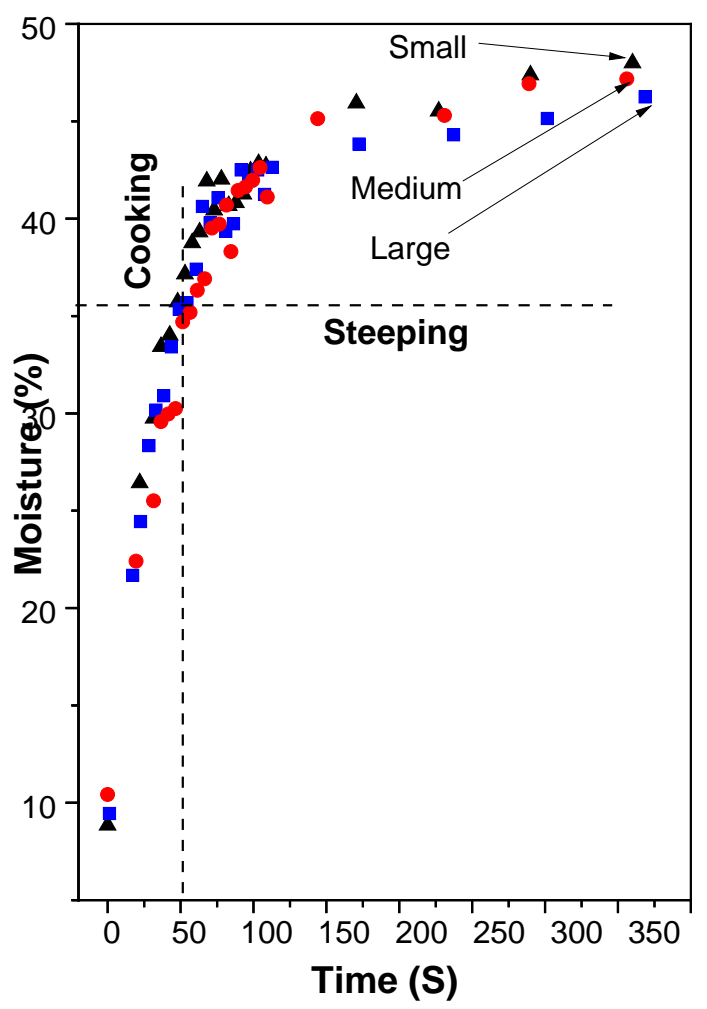

Figure 5. Moisture content of large, medium, and large Puma maize grains as a function of time, for the cooking and steeping steps.

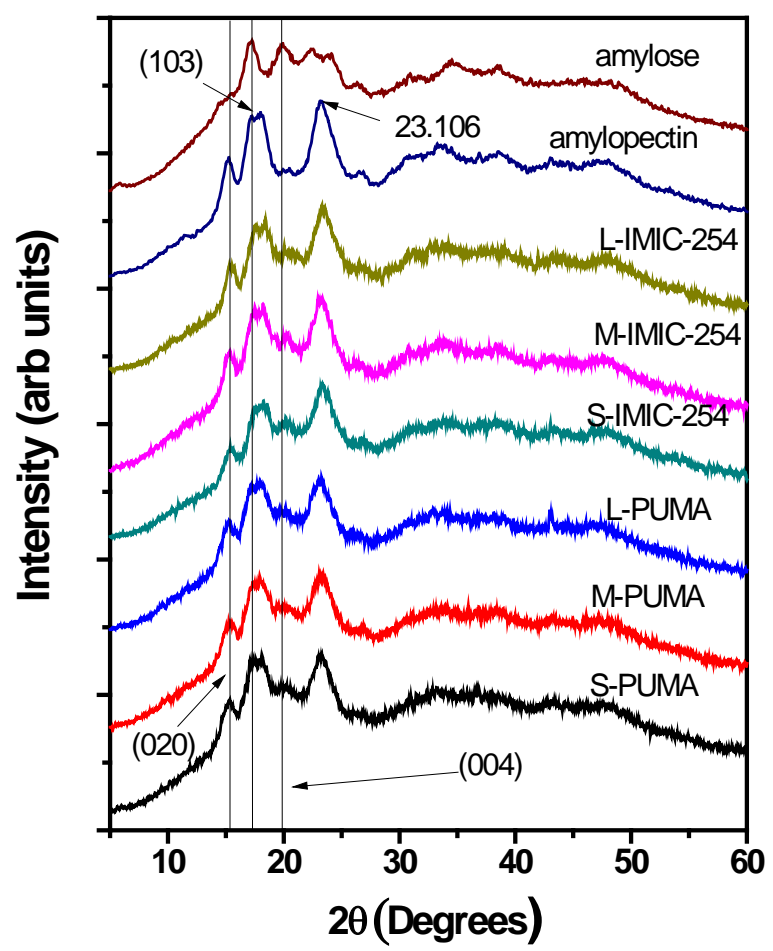

Figure 6. X-ray diffraction patterns of isolated starches from small, medium, and large maize grains for IMIC-254 and Puma, as well as amylopectin and amylose from Sigma Aldrich taken as reference. 
PUMA

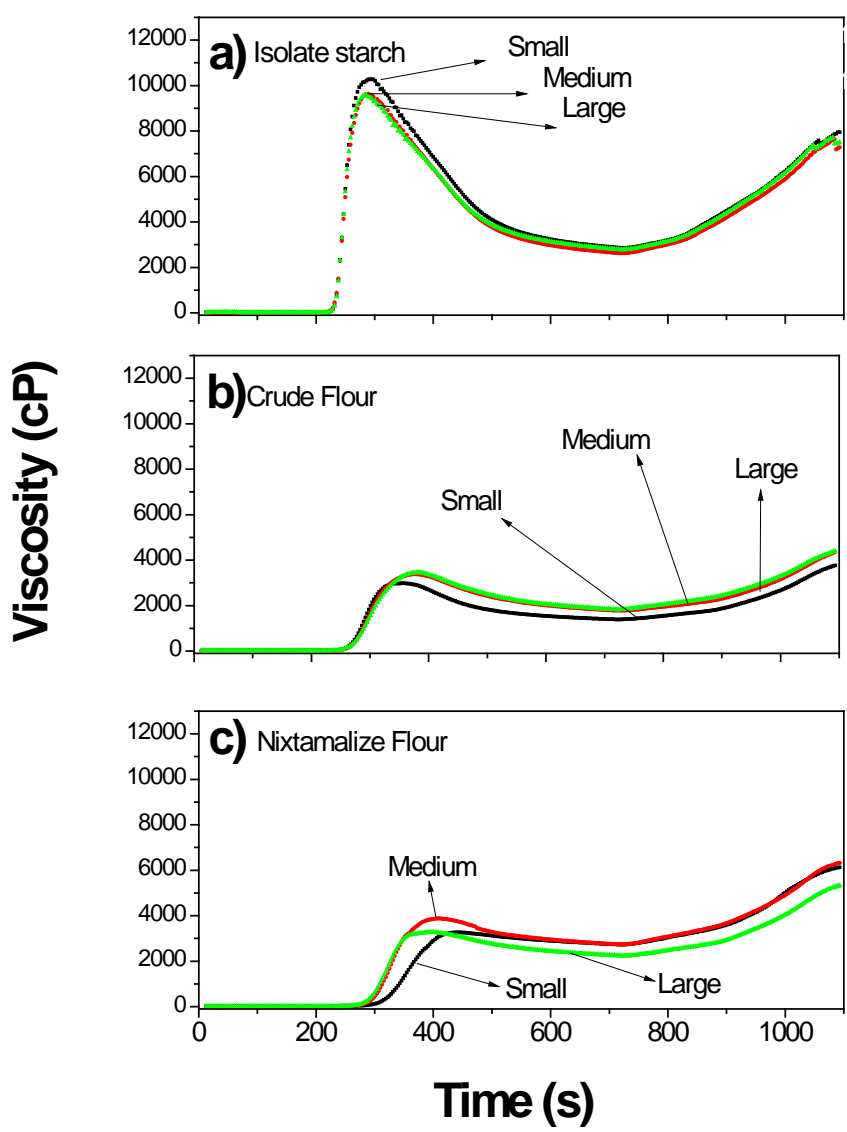

IMIC-254
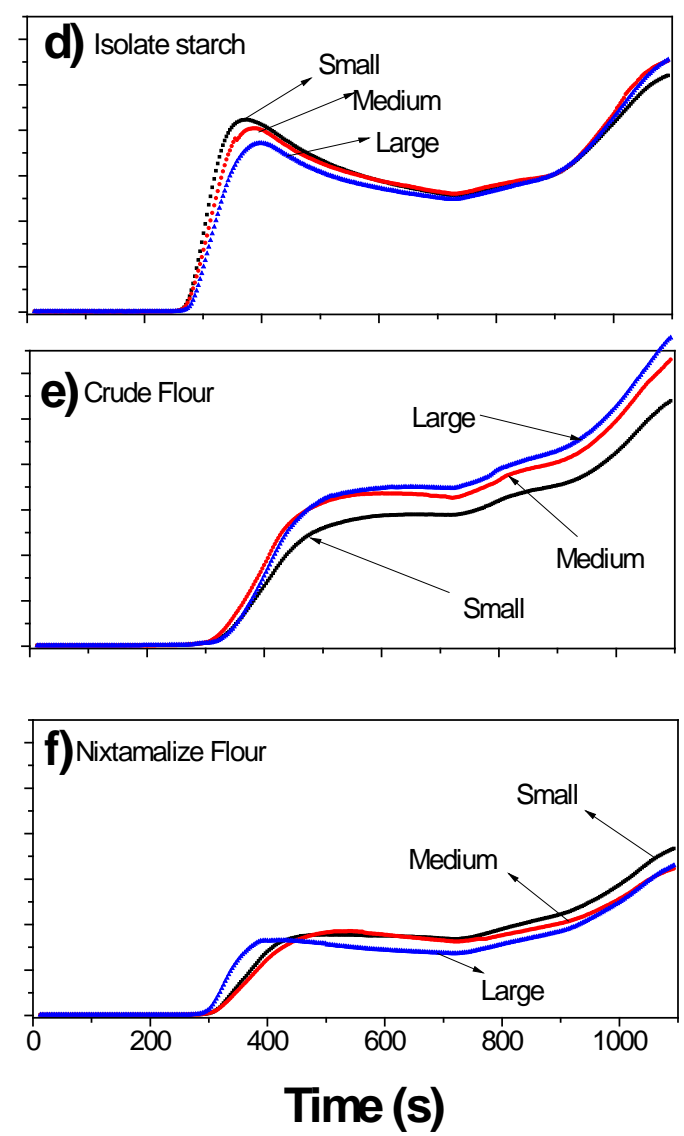

Figure 7. A to F shows the pasting profiles of isolated starches, the crude maize flours, as well as nixtamalized maize flours obtained from small, medium and large Puma and IMIC-254 grains as a function of the time.

\section{Conclusions}

The harvest of the corn maize grains includes small, medium, and large grains, and in some cases, due to the processing conditions, the separation of the grains by sizes produces the reduction of the accepted grains. According to the results mentioned above, it is clear that in the case of the hybrids studied in this work, the isolated starches from small, medium, and large maize grains have the same size distribution and shape. The chemical composition shows that small grains have a low amount of fat which can be related to the germ development in the cob, and low fiber content. About the cooking time, this parameter was affected by size; small grains had a lower cooking time. In the case of small grains, these reached the $46 \%$ of moisture in shorter time. Statistically, the hardness of the grain does not have grain size dependence. The Megazime test showed that isolated starches for large grains of both hybrids had the bigger amount of amylopectin; these results were confirmed by X-ray diffraction studies. Calcium uptake in small and medium grains is higher than in large grains, it could be related to the area/volume ratio. No significant differences in the pasting profile of nixtamalized flours obtained from these three different grains sizes were found.

From an industrial point of view, it is possible to have nixtamalized products such as corn flour with the same physicochemical and rheological properties using different grain sizes, but the moisture content showed that it is very important to take care of the cooking and steeping time. Small grains reach the final moisture content in less time. This is an important fact because it reduces the total time of the process before wet milling. A combination of different parameters such as moisture, cooking time, and calcium content permits to obtain products with different grains sizes and the same functional properties. 


\section{Acknowledgements}

This research was supported by MASAGRO (Modernizacion Sustentable de la Agricultura), a program of the SAGARPA-Mexico. The authors would like to thank Dra. Carmen Peza from the CFATA-UNAM, Mexico for her technical support. Margarita Contreras-Padilla would like to thank to CONACYT by her postdoctoral position in CFATA-UNAM. Natalia Rincon and Sandra M. Londoño want to thank CONACYT Mexico for the financial support of their master studies.

\section{References}

[1] Duarte, A., Mason, S., Jackson, D. and Kiehl, J. (2005) Grain Quality of Brazilian Maize Genotypes as Influenced by Nitrogen Level. Crop Science, 45, 1958-1964. http://dx.doi.org/10.2135/cropsci2004.0587 http://digitalcommons.unl.edu/cgi/viewcontent.cgi?article=1114\&context=foodsciefacpub

[2] Vázquez-Carrillo, G., Santiago-Ramos, D., Salinas-Moreno, Y., Rojas-Martínez, I., Arellano-Vázquez, J.L., Velázquez-Cardenas, G.A. and Espinosa-Calderon, A. (2012) Interaccin genotipo-ambientedel rendimiento y calidad de grano y tortilla de hibridos de maíz en valles altos de Tlaxcala, México [Genotype-Environment Interaction of Yield and Grain and Tortilla Quality of Maize Hybrids at the Highlands of Tlaxcala, México]. Revista Fitotécnica Mexicana, 35, 229-237. https://www.researchgate.net/publication/260437277

[3] Miranda, A., Vásquez-Carrillo, G., García-Lara, S., San Vicente, F., Torres, J.L., Ortiz-Islas, S., Salinas-Moreno, Y. and Palacios-Rojas, N. (2013) Influence of Genotype and Environmental Adaptation into the Maize Grain Quality Traits for Nixtamalization. CyTA—Journal of Food, 11, 54-61. http://dx.doi.org/10.1080/19476337.2013.763862

[4] Gutiérrez, E., Rojas-Molina, I., Pons-Hernández, J.L., Guzmán, H., Aguas-Ángel, B., Arenas, J., Fernández, P., Palacios-Fonseca, A., Herrera, G. and Rodríguez, M.E. (2007) Study of Calcium Ion Diffusion in Nixtamalized Quality Protein Maize as a Function of Cooking Temperature. Cereal Chemistry, 84, 186-194. http://dx.doi.org/10.1094/CCHEM-84-2-0186

[5] Rojas-Molina, I., Gutierrez-Cortez, E., Palacios-Fonseca, A., Baños, L., Pons-Hernández, J.L., Pineda-Gómez, P. and Rodríguez-Garcia, M.E. (2007) Study of Structural and Thermal Changes in Endosperm of Quality Protein Maize During Traditional Nixtamalization Process. Cereal Chemistry, 84, 304-312. http://dx.doi.org/10.1094/CCHEM-84-4-0304

[6] Palacios-Fonseca, A.J., Vazquez-Ramos, C. and Rodríguez-García, M.E. (2009) Physicochemical Characterizing of Industrial and Traditional Nixtamalized Corn Flours. Journal of Food Engineering, 93, 45-51. http://www.sciencedirect.com/science/article/pii/S0260877408006122 http://dx.doi.org/10.1016/j.jfoodeng.2008.12.030

[7] AACC (2000) Approved Methods. American Association of Cereal Chemists, St. Paul, MN, USA. Methods 46-13.

[8] AOAC (2000) Official Methods of Analysis. 17th Edition, The Association of Official Analytical Chemists, Gaithersburg, MD, USA. Methods 925.10, 65.17, 974.24, 992.16.

[9] AACC (2000) Approved Methods. American Association of Cereal Chemists, St. Paul, MN, USA. Methods 08-01 30-25 and 46-13.

[10] AOAC (1998) Official Methods of Analysis. 16th Edition, Official Association of Official Analytical Chemists, Maryland, USA. Method 968.08.

[11] McCleary, B.V., Solah, V. and Gibson, T.S. (1994) Quantitative Measurement of Total Starch in Cereal Flours and Products. Journal of Cereal Science, 20, 51-58. http://dx.doi.org/10.1006/jcrs.1994.1044 http://www.sciencedirect.com/science/article/pii/S0733521084710447

[12] Gibson, T.S., Solah, V.A. and McCleary, B.V. (1997) A Procedure to Measure Amylose in Cereal Starches and Flours with Concanavalin. American Journal of Cereal Science, 25, 111-119. http://dx.doi.org/10.1006/jcrs.1996.0086 http://www.sciencedirect.com/science/article/pii/S0733521096900867

[13] Valderrama-Bravo, C., Rojas-Molina, A., Gutiérrez-Cortez, E., Rojas-Molina, I, Oaxaca-Luna, A, De la Rosa-Rincón, E. and Rodríguez-García, M.E. (2010) Mechanism of Calcium Uptake in Corn Kernels During the Traditional Nixtamalization Process: Diffusion, Accumulation and Percolation. Journal of Food Engineering, 98, 126-132. http://www.sciencedirect.com/science/article/pii/S0260877409006116 http://dx.doi.org/10.1016/j.jfoodeng.2009.12.018

[14] Imberty, A., Chanzy, H., Perez, S., Burleon, A. and Tran, V. (1988) The Double-Helical Nature of the Crystalline Part of A-Starch. Journal of Molecular Biology, 201, 365-378. http://www.ncbi.nlm.nih.gov/pubmed/3418703 http://dx.doi.org/10.1016/0022-2836(88)90144-1

[15] Fernández-Muñoz, J.L., Rojas-Molina, I., González-Dávalos, M.L., Leal, M., Valtierra, M.E., San Martín-Martínez, E. and Rodríguez, M.E. (2004) Study of Calcium Ion Diffusion in Components of Maize Kernels During Traditional Nixtamalization Process. Cereal Chemistry, 81, 65-69. http://dx.doi.org/10.1094/CCHEM.2004.81.1.65 